\title{
Prostato-inguinal fistula: An unusual site of voiding
}

\author{
Madhusudan Patodia, MD; Manoj Kumar, MD; Satyanarayan Sankhwar, MD; Apul Goel, MD; \\ Siddharth Singh, MD; Bimalesh Purkait, MD
}

Department of Urology, King George Medical University, Lucknow, India

Cite as: Can Urol Assoc J 2015;9(11-12):E821-2. http://dx.doi.org/10.5489/cuai.3204 Published online November 4, 2015.

\section{Abstract}

An 8-year-old boy presented with voiding from the right inguinal region, which on evaluation was diagnosed as prostato-inguinal fistula. We discuss the pathophysiology of this fistula.

\section{Case report}

An 8-year-old boy presented with voiding from a fistulous opening in the right inguinal region for 7 days. Three months before, he was involved in a road accident at which he sustained left femur neck fracture that required a screw placement. There was no urethral injury and he voided normally after the trauma. Urethral catheter was placed after orthopedic surgery which remained in situ for 2.5 months and the catheter was changed 3 times during this period. The child also had skin loss over the right flank for which skin grafting was done. His urethral catheter was removed 15 days later, after which he developed decreased urinary stream and a urinary fistula in the right inguinal region from where he passed urine with stream (Fig. 1). Urethral calibration with a 10-Fr catheter failed and suprapubic catheter was placed as urinary diversion. Five days later, an antegrade (Fig. 2) and retrograde cysto-urethrography (Fig. 3) showed communication between the prostatic urethra and right inguinal region. After 21 days of suprapubic catheterization, a micturating cystourethrogram MCU was performed, which showed a healed fistula. The patient is now scheduled to undergo an end-to-end anastomotic urethroplasty.

\section{Discussion}

Prostato-cutaneous fistulae are rare and may occur as a result of trauma, surgery, malignant disease, or chronic inflamma- tion. The most common sites for urinary fistulae are vagina, rectum, bowel, abdominal wall, scrotum, or perineum. ${ }^{1}$ Previously, 4 cases of prostato-cutaneous fistula have been reported, all extending into the thigh/perineum. The causes were open prostatectomy, ${ }^{2}$ transurethral prostate resection, ${ }^{3}$ following surgical intervention for neurogenic bladder, ${ }^{4}$ and multiple urethral dilations. ${ }^{5}$

Anatomically, such fistulous tracts extend into retro-pubic space through fat and open just lateral to strong rectus muscle and sheath. The cause of the fistula in our patient was difficult to explain and probably resulted from a stricture that developed at the membrano-bulbous region. Possibly, stricture and long-term catheterization caused prostatic abscess, which burst and found its path through the retro-pubic fat and finally opened in the right inguinal region where more resistant rectus sheath ends.

\section{Conclusion}

This is the first pediatric case of prostato-inguinal fistula. All previous reports explain prostato-cutaneous fistula tract opening into the thigh or perineum. In this case, we explained the pathophysiology of the inguinal route of the prostato-cutaneous fistula.

Competing interests: The authors declare no competing financial or personal interests.

This paper has been peer-reviewed.

\section{References}

1. Singh A, Marshall FF. Urinary fistulas. In Gillenwater JY, Grayhack JT, Howards SS, Duckett JW eds, Adult and Pediatric Urology. 2nd ed. Vol II. St Louis: Mosby Year Book; 1992:1119-34.

2. Snooks SJ, Dharmasena F, Mitchell TJ, et al. Prostatocutaneous urinary fistula to the thigh after retropubic prostatectomy in a patient with polycythaemia rubra vera. Br J Urol 1986;58:558. http://dx.doi. org/10.1111/i.1464-410X.1986.tb05469.x

3. Price AJ, Bates TS, Deveraj V, et al. An unusual prostatocutaneous fistula. Br J Urol 1997;80:509-10. http://dx.doi.org/10.1046/i.1464-410X.1997.t01-1-00390.x 


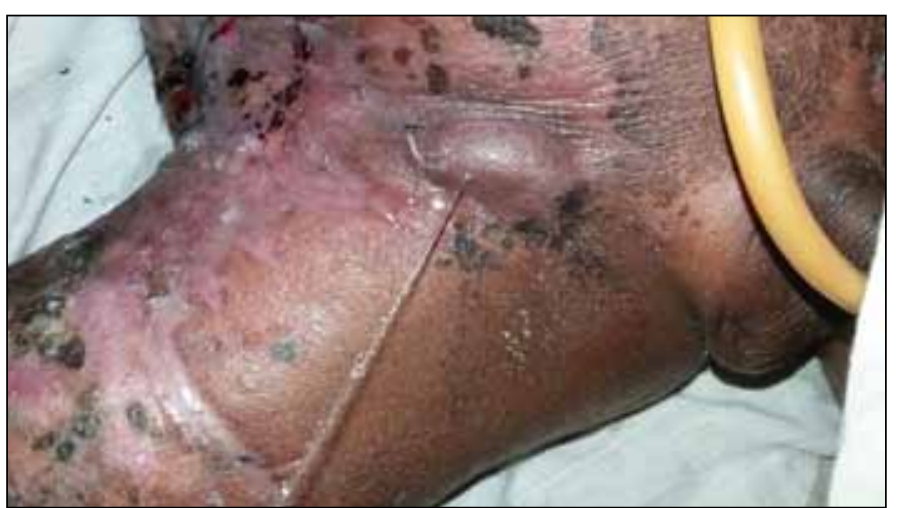

Fig. 1. Right inguinal region showing voiding from the fistulous opening.

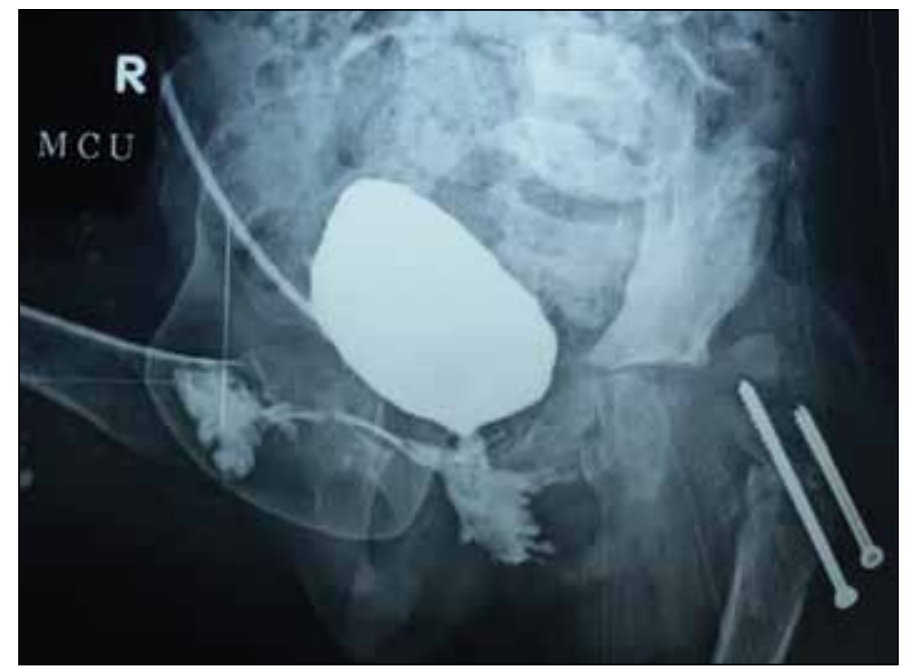

Fig. 2. Micturating cystourethrogram demonstrating fistula between prostatic urethra and right inguinal region. No contrast is seen beyond the prostatic/ membranous urethra. The prostatic fossa is large and irregular.

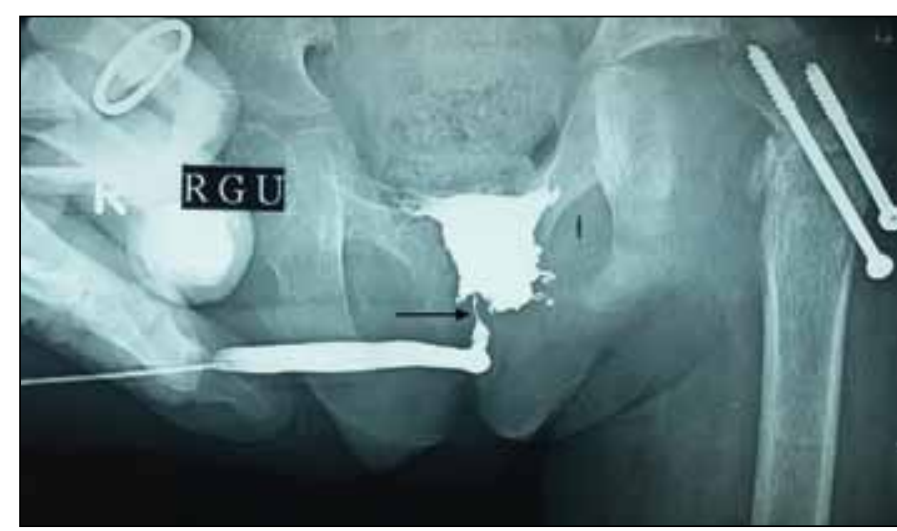

Fig. 3. Retrograde urethrogram showing contrast pooling in prostatic fossa and narrowing/stricture just before it (arrow).
4. Yohannes $P$, Khan $A$, Francis $K$, et al. Robot-assisted Bricker ileoureteral anastomosis during intracorporeal laparoscopic ileal conduit urinary diversion for prostatocutaneous fistula: Case report. J Endourol 2004;18:269-72. http://dx.doi.org/10.1089/089277904773582886

5. Kumar N, Vasudeva P, Kumar A, et al. Prostato-cutaneous fistula: A rare clinical entity. Urology 2013;82:e910. http://dx.doi.org/10.1016/i.urology.2013.04.023

Correspondence: Dr. Apul Goel, Department of Urology, King George Medical University, Lucknow, India; drapul.goel@gmail.com 